\title{
Objective measuring technique for teat dimensions of dairy cows
}

I. Zwertvaegher ${ }^{a^{*}}$, J. Baert ${ }^{\mathrm{a}}$, J. Vangeyte ${ }^{\mathrm{a}}$, A. Genbrugge ${ }^{\mathrm{a}}$, S. Van Weyenberg ${ }^{\mathrm{a}}$

${ }^{a}$ Institute for Agricultural and Fisheries Research, Technology and Food Science Unit, Agricultural Engineering, Burgemeester Van Gansberghelaan 115, 9820 Merelbeke, Belgium

* Corresponding author: Ingrid Zwertvaegher, Institute for Agricultural and Fisheries Research, Technology and Food Science Unit, Agricultural Engineering, Burgemeester Van Gansberghelaan 115, 9820 Merelbeke, Belgium, Tel: (0032)92722813, Fax: (0032)92722801, email: Ingrid.Zwertvaegher@ilvo.vlaanderen.be

\begin{abstract}
The interaction between teat and the teatcup liner can strongly affect the milking characteristics and udder health of dairy cows. Therefore, teat morphology is an important parameter in choosing the most appropriate liner. Nevertheless, information on teat morphology is scarce and rarely sufficient for liner selection. Current techniques for measuring teat morphology are subjective, not always accurate and time consuming, and gathering such information on large scale is difficult. This study presents a new vision based measuring technique that uses a camera to obtain a 2D image of the teat and image processing analysis to determine teat length and diameters. The technique was shown to be accurate. Errors were generally limited to 5\% for both teat length and diameters and were less than $2 \%$ when the angle of the teat in the longitudinal direction was small.
\end{abstract}

Keywords: measuring technique; image processing; accuracy; teat length; teat diameter; dairy cow

\section{Nomenclature}

$\alpha \quad$ angle of the teat in the transverse direction $\left({ }^{\circ}\right)$

$\beta \quad$ angle of the teat in the longitudinal direction $\left(^{\circ}\right)$

c1 centre at $33 \%$ of the teat length

c2 centre at $80 \%$ of the teat length

D distance from the lens centre to the centre of the teat insertion opening $(\mathrm{mm})$

$d^{p} \quad$ measured teat diameter of the final 2D teat shape $(T)$ (pixel)

$d^{p, c} \quad$ measured teat diameter of the final 2D teat shape $(T)$ corrected for the angle in the transverse direction (pixel)

$d^{w, c} \quad$ measured teat diameter of the final 2D teat shape $(T)$ corrected for the angle in the transverse direction $(\mathrm{mm})$

$f(m, n)$ intensity of the pixel located in the $\mathrm{m}^{\text {th }}$ column, $\mathrm{n}^{\text {th }}$ row of the geometrical teat shape $\left(G_{t}\right)$

$G_{t} \quad 2 \mathrm{D}$ teat shape after thresholding 
teat length $(\mathrm{mm})$

$l^{p} \quad$ measured teat length of the final 2D teat shape (T) (pixel)

$l^{p, c} \quad$ measured teat length of the final 2D teat shape $(T)$ corrected for the angle in the transverse direction (pixel)

$l^{w, c} \quad$ measured teat length of the final 2D teat shape $(T)$ corrected for the angle in the transverse direction $(\mathrm{mm})$

$t \quad$ threshold

$T \quad$ final two-dimensional teat shape after cleaning operations

\section{Introduction}

During machine milking, the forces applied on the teats result in physiological and pathological changes, which may counteract the normal teat defence mechanism. Consequently, the teats may become more sensitive for the entry of pathogens with intramammary infections as a result. Therefore, the condition of the teat plays a considerable role in the incidence of mastitis infections (Bhutto, Murray, Woldehiwet, 2010; Gleeson, O'Callaghan, Rath, 2004). Besides the greater risk on penetration of bacteria into the udder, these changes in teat condition are generally accompanied by discomfort and pain, which negatively influence the milking process. The design of the teatcup liner has a larger effect on teat tissue changes than other machine settings (Gleeson et al., 2004). In addition, the liner design has proven to have a great influence on milking characteristics (Mein, Reinemann, O'Callaghan, Ohnstad, 2003). Consequently, the selection of teatcup liners is a crucial part of good milking management. Because of the interaction between teat and teatcup liner, teat morphology is an important parameter in choosing the most suitable liner for a herd. Yet, to date, liners are usually chosen on a 'trial and error' basis (de Koning, Ronningen, Bjerring, Ipema, 2003). Teat morphology is seldom considered in choosing the most suitable liner, mostly because of the lack of knowledge.

Various methods to measure teat morphology have been described. Until today, the most common method to determine teat dimensions, and udder morphology in general, is on sight scoring (World Holstein-Friesian Federation, 2005; Zavadilova, Stipkova, Nemcova, Bouska, Matejickova, 2009). The results of this technique are, however, biased by the operator and the standard used (Sapp, Rekaya, Bertrand, 2003). More objective methods have been used to determine teat length and teat diameter, such as measuring tapes, callipers and transparent open-ended tubes with graduated scales (Bakken, 1981; McKusick, Berger, Thomas, 1999; Rovai, Kollmann, Bruckmaier, 2007; Tilki, Inal, Colak, Garip, 2005). Teat diameters can also be measured using a cutimeter, by removing the calliper spring or by holding the jaws open manually to neutralise the spring pressure (Hamann, Mein, Nipp, 1996). An electronic calliper device, an improved version of the cutimeter, has been developed to measure changes in teat end thickness in response to changes in the applied pressure. Because the 
recordings start at a very low pressure $(0.125 \mathrm{kPa})$, the first readings are a measurement of the diameter of the teat apex (Hamann, Nipp, Mein, 1988). Another method used to measure teat morphology and teat tissue changes is ultrasonography (Ambord \& Bruckmaier, 2010; Neijenhuis, Klungel, Hogeveen, 2001; Paulrud, Clausen, Andersen, Rasmussen, 2005; Seker, Risvanli, Yuksel, Saat, Ozmen, 2009). This method requires an experienced observer and substantial measuring time and has therefore been restricted to experimental conditions (de Koning et al., 2003). Apart from scoring and ultrasonography, all methods described so far also have the disadvantage of providing per single measurement only one value at one point. Consequently, multiple measurements are needed to evaluate the whole teat; as a result the gathering of information on a large scale is not possible. Furthermore, the accuracy and the repeatability of the methods can be questioned since the results of the measurements depend on the position of the measuring tool on the teat and the moment of measurement; measurements during teat contractions should be avoided (Hamann et al., 1988).

An objective measuring technique capable of measuring teat dimensions accurately, with precision and speed, and with reduced effort for the operator, would be a large step forward in collecting data on teat morphology. Such a technique could be applied by control and consulting organisations either as a handheld system or implemented in automatic milking systems, helping the farmer select the most suitable liner for the herd or, if possible, for a specific cow or perhaps even individual teats. The acquired data could also be used to select more uniform teat dimensions, which might eventually simplify liner choice. Furthermore, a fast and accurate measuring device may be used to investigate the relationship between teat dimensions and udder health. The technique could serve as a useful tool to evaluate milking machines in combination with other monitoring systems, such as milk flowmeters. The progress of digital technology and image analysis software offers new perspectives in this area. An image analysis technique has already been proposed to measure udder morphology in dairy ewes (Marie-Etancelin et al., 2002). The technique is more objective compared to scoring and appears to be very promising. However, the application of the technique is elaborate and, for the moment, only possible to use under experimental conditions.

The aim of this study was to develop an objective and easy-to-use vision based measuring technique that was capable of providing numerous measurements of the whole teat.

\section{Materials and methods}

\subsection{Measuring device and technique}

A Super Video Graphics Array camera IEEE1394 (Guppy F-046B, Allied Vision Technologies, Stadtrod, Germany) with a fixed $25 \mathrm{~mm} \mathrm{C}$-mount lens was mounted at the end of a rectangular extruded aluminium profile (120 mm x $60 \mathrm{~mm}$ x $750 \mathrm{~mm}, 3 \mathrm{~mm}$ thickness) (Fig. 1). Opposite to the 
camera, a circular opening of $50 \mathrm{~mm}$ i.d. was provided in the housing for insertion of the teat. In a previous study (Baert, Maertens, Vangeyte, Sonck, 2007), an opening of this size proved to be large enough to place the teat sufficiently deep in the device to acquire a good image for adequate teat length measurements. Images of the teats were made while each teat was inserted separately in the measuring device so that the upper side of the device was pressed gently against the udder. The $50 \mathrm{~mm}$ opening thus defines the teat base. The distance from the centre of the opening to the lens centre was fixed $(550 \mathrm{~mm})$. An LED illuminated background at the back of the profile generated high contrasting contours of the teats. This high contrast provided a sharp edge of the contour, necessary for accurate and automated image analysis. The camera was triggered by a push button on the housing that simultaneously switches on the LED-background illumination. The camera and the LEDs were powered by a 4-cell lithium polymer battery $(14.4 \mathrm{~V}, 2000 \mathrm{~mA})$. Electronics stabilised the voltage for the LEDs and the trigger signal. The camera and lens settings were kept constant (shutter, gain, focus and diaphragm) to maintain standard image quality, necessary for comparison between the images. A rugged, waterproof tablet PC (E100, Getac, Düsseldorf, Germany), connected to the camera through USB 2.0, was used for controlling the camera, automatic storing of the images and visual control of the images of the teats. The latter was needed to make sure the images meet the requirements necessary for further image processing.

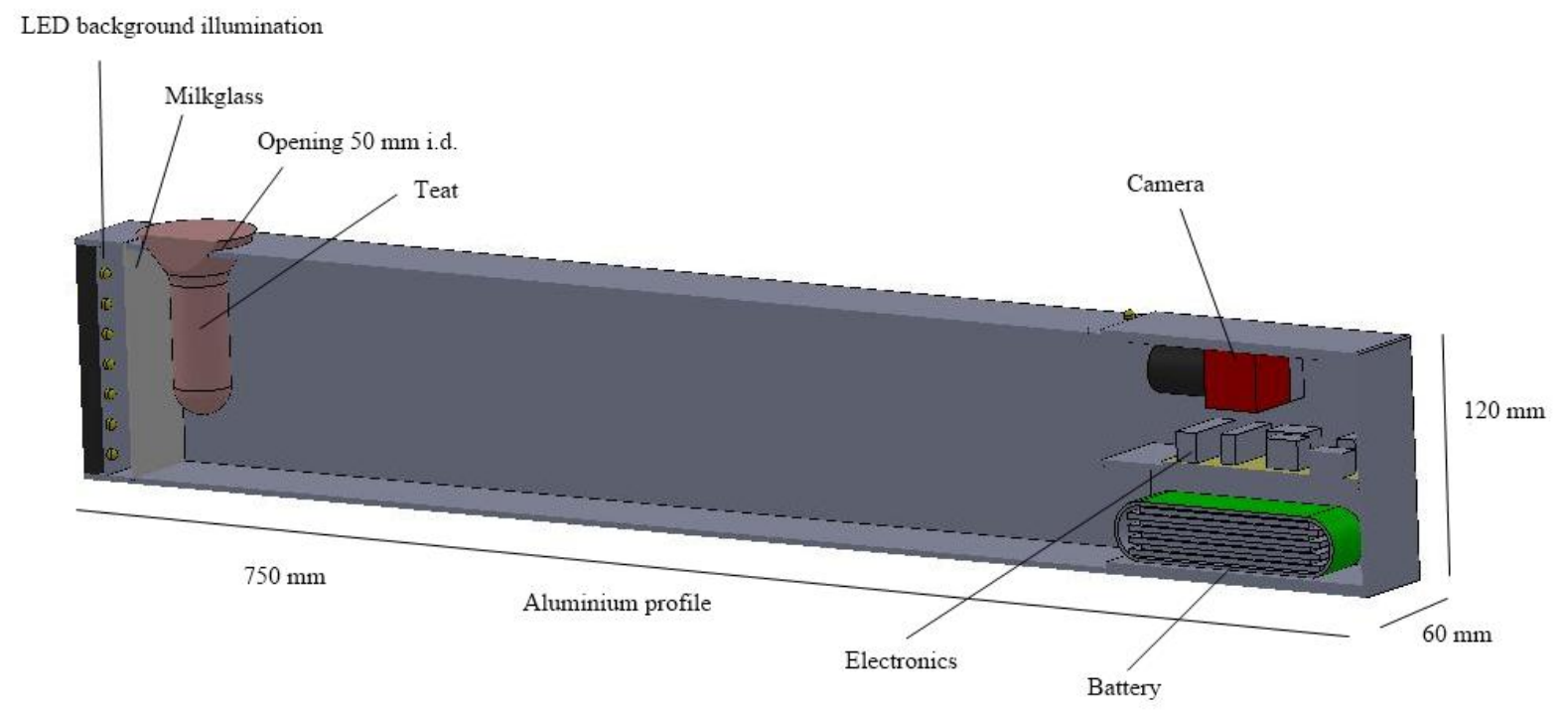

Fig. 1 - Cross-section of the vision based measuring device for teat dimensions.

\subsection{Vision based analysis}

The image analysing software used was developed using Halcon 8.0 (MVTec Software GmbH, München, Germany). A fixed rectangular region of interest was defined in the raw image to eliminate 
the redundant image fraction. With constant light conditions and high contrast between subject and background, the 8-bit greyscale image can be accurately binarised with a fixed threshold $(t)$.

$G_{t}=\{f(m, n): f(m, n)<t\}$

With $f(m, n)$ the intensity of the pixel located in the $m^{\text {th }}$ column, $n^{\text {th }}$ row. $G_{t}$ represents the geometrical teat shape but still contains unwanted structures such as hair and dirt spots on the background. An opening operator with circular structural element removed most of these unwanted structures. Larger dirt spots were removed based on area size of the discontented regions. The resulting 2D binary teat shape $(T)$ is used for analysing length and diameter of the teat.

The length $l^{p}$ in pixels is calculated from the highest to the lowest position of $T$ :

$l^{p}=\operatorname{Max}(n) \in T-\operatorname{Min}(n) \in T$

The diameter $d^{p}$ in pixels is calculated at a relative length from the base of the teat:

$d_{i}^{p}=\sum_{m} T\left(l_{i}^{p}, m\right)$

With $l_{i}^{p}=\operatorname{Max}(n) \in T-\left\lceil i \frac{l^{p}}{100}\right\rceil(i \in Z \mid 0 \leq i \leq 100)$

To maintain high accuracy, the diameters and length were corrected for the position of the teat in the measuring device and for the distance of the teat to the camera. Since the angle of the teat in the transverse direction $(\alpha)$ can cause inaccuracies, this angle was determined so a correction factor can be added to the length and the diameters. The angle $\alpha$ was calculated by determining the centres ( $c 1$ and c2) of the sections at $33 \%$ and $80 \%$ of the length of the teat (Fig. 2):

$\alpha=\arctan \left(\frac{x_{c 1}-x_{c 2}}{y_{c 1}-y_{c 2}}\right)$

With

$x_{c i}=\sum_{m} T\left(l_{i}^{p}, m\right) \cdot m / d_{i}^{p}$

$y_{c i}=i \frac{l^{p}}{100} \quad i \in\{33,80\}$ 


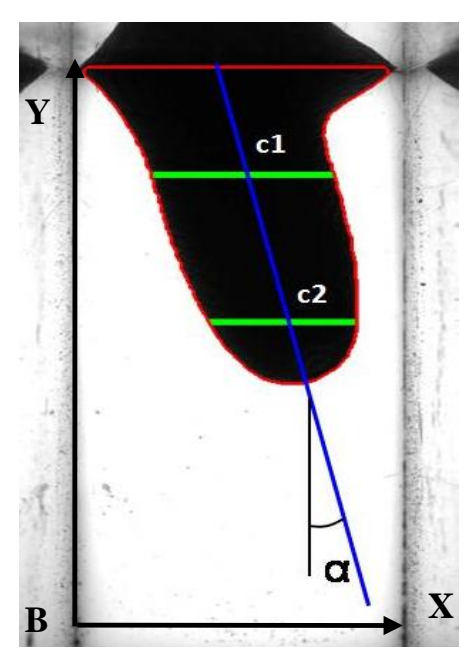

Fig. 2 - Calculation of the angle of the teat in the transverse direction $(\alpha)$ by determining the centres of the sections at $33 \%$ (c1) and $80 \%$ (c2) of the teat.

The corrected diameters $d^{p, c}$ and lengths $l^{p, c}$ were:

$l^{p, c}=\frac{l^{p}}{\cos (\alpha)}$

$d_{i}^{p, c}=d_{i}^{p} \cos (\alpha)$

Real world dimensions $\left(l^{w, c}, d^{w, c}\right)$ were obtained by conversing the pixel dimensions. The resolution of objects at the distance of $550 \mathrm{~mm}$ is $0.189 \mathrm{~mm}_{\text {pixel }}{ }^{-1}$.

\subsection{Accuracy}

The image analysing software automatically corrected for deviations of the teat measurements due to the position in the transverse direction. However, the angle of the teat in the longitudinal direction $(\beta)$ (towards or away from the camera) can also cause errors in the measured teat length and teat diameter. The error on the teat length made by $\beta$ (Fig. 3) can be calculated by using the following equation:

error $=\left(\frac{l^{w, c}-1}{l}\right) \cdot 100$

with $\quad l^{w, c}=$ measured teat length $=\left(\frac{\mathrm{l} \cos \beta}{\mathrm{D}-\mathrm{l} \sin \beta}\right) \mathrm{D}$

$l=$ actual teat length

$\mathrm{D}=$ constant $=$ distance from the lens centre to the centre of the teat insertion opening. 


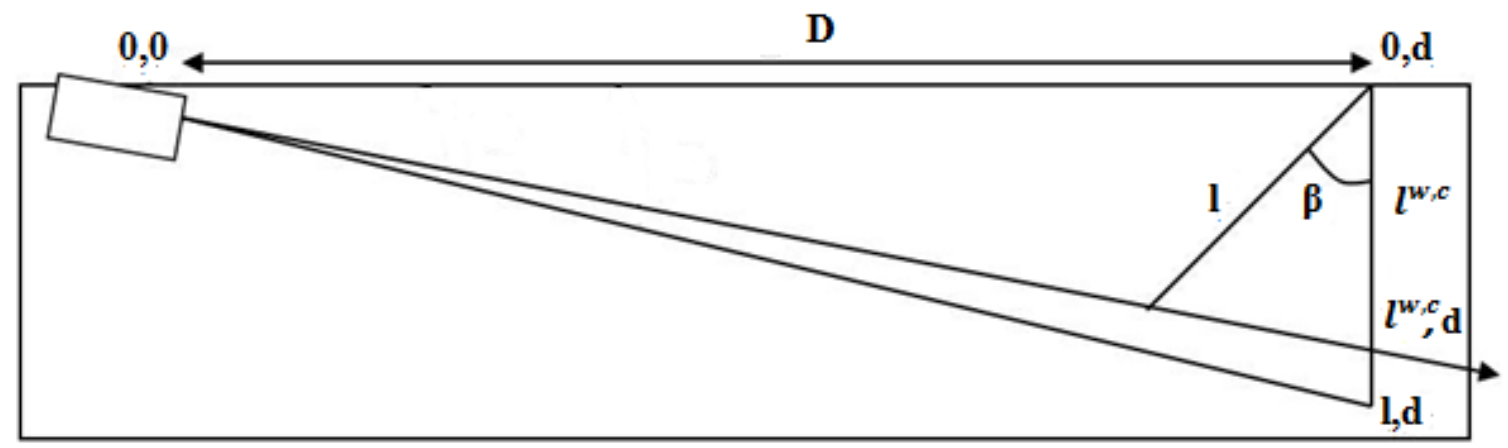

Fig. 3 - Calculation of the error made on the teat length by the measuring device due to the angle in the longitudinal direction $(\beta)$.

Deviations of teat length due to movements in longitudinal direction from $-20^{\circ}$ to $0^{\circ}$ (away from the camera) and $0^{\circ}$ to $30^{\circ}$ (towards the camera) were calculated for different teat lengths varying from 30 mm until $100 \mathrm{~mm}$, which is the range of teat length found in literature, using Eq. 10.

The error on teat diameters made by the measuring device due to the angle the teat makes in the longitudinal direction could not be calculated since this angle was unknown. The accuracy of the measuring technique for teat diameters in the longitudinal direction was therefore obtained by analysing the images of four artificial teats of known dimensions, positioned at different angles relative to the camera. The artificial teats consisted of $200 \mathrm{~mm}$ long steel cylinders, respectively 20, 28,36 and $44 \mathrm{~mm}$ in diameters at the barrel and a radius of the sphere of $12.5 \mathrm{~mm}$ at the apex. The dimensions were chosen to represent the range of teat dimensions in Holstein cows. The artificial teats were attached to a protractor. The design of protractor and artificial teats allowed the teats to rotate around pivoting points. To examine the influence of teat length a total of four pivoting points were present in the cylinders, located at respectively 30,50, 70 and $90 \mathrm{~mm}$ from the apex. The artificial teats were placed straight in the device (i.e. angle of $0^{\circ}$ ). Images were taken at incremental steps of $5^{\circ}$, ranging from $0^{\circ}$ to $30^{\circ}$ towards the camera and to $20^{\circ}$ away from the camera. Errors on teat diameters were determined at $75 \%, 50 \%, 25 \%$ and $10 \%$ of the teat length, starting from the teat end (D75, D50, D25 and D10), by comparing the measured diameters relative to the actual teat diameters.

Statistical analyses were performed using IBM SPSS Statistics 19 (SPSS Inc. 2010, IBM corporation, New York, USA). Linear regression was used to investigate whether the measured diameter by the measuring device and the angle of the teat in the longitudinal direction $(\beta)$ (independent variables) could be used to predict the actual teat diameter at $75 \%, 50 \%, 25 \%$ and $10 \%$ of the teat length (dependent variables). A three-way ANOVA with actual length of the teat, actual diameter of the teat, $\beta$ and their interactions as fixed factors was performed on the percentage deviation on teat diameters at 
$75 \%, 50 \%, 25 \%$ and $10 \%$ of the teat (dependent variables). If significant, Scheffé post hoc tests were performed. All data were reported as means. Statistical significance was considered when $\mathrm{P}<0.05$.

Preliminary tests were performed in different types of milking parlours to assess the practical use, robustness, and ergonomic aspects of the measuring device and to evaluate the image processing analyses on real teats. The first test was done in a tie-stall; 70 teats from 18 cows were measured. A second test consisted of measuring the teats of 90 cows (352 teats in total) in a side-by-side milking parlour with automatic detachment of the units. A third series of tests was performed at six different herds ( 1 tandem, 5 herringbone parlours) where in each herd 10 randomly chosen cows were measured.

\section{Results}

\subsection{Teat length}

Errors were less than $2 \%$ when the teat was put straight in the device or at small angles $\left(-5^{\circ}\right.$ to $\left.+15^{\circ}\right)$. Errors were limited to $5 \%$ in most cases (Table 1). However, larger errors (up to 11\%) were possible with angles greater than $25^{\circ}$ and $15^{\circ}$, towards and away from the camera, respectively. Under most conditions teat length was underestimated. Only when the teat was directed at the camera at small angles $\left(5^{\circ}\right.$ to $\left.15^{\circ}\right)$, and for teats of certain length, was the length overestimated. At the same angle, the calculated error for teats of equal length was greater for teats tilted away from the camera compared to those pointed towards the camera. For teats positioned away from the camera the error was smaller for shorter teats than for larger teats. For teats of the same length, the error rapidly increased with increasing angle. The association was less straightforward for teats that pointed in the direction of the camera. At large angles, the deviation of the calculated length compared to the actual length decreased with teat length and increased with increasing angle. 
Table 1 - Percentage deviation on teat length due to the angle in the longitudinal direction $\left(-20^{\circ}\right.$ to $30^{\circ}$ towards the camera) for teats of different length (30 to $100 \mathrm{~mm}$ ), with deviations > 5\% in bold and > $10 \%$ in bold and italic, determined using Eq. 10.

\begin{tabular}{|l|ccccccccccc|}
\hline $\begin{array}{l}\text { Teat } \\
\text { length } \\
(\mathrm{mm})\end{array}$ & \multicolumn{7}{|c|}{ Angle in the longitudinal direction of the camera $\left(^{\circ}\right)$} \\
\cline { 2 - 11 } & -20 & -15 & -10 & -5 & 0 & 5 & 10 & 15 & 20 & 25 & 30 \\
\hline 30 & $\mathbf{- 7 . 8}$ & -4.8 & -2.4 & -0.9 & 0.0 & 0.1 & -0.6 & -2.0 & -4.2 & $\mathbf{- 7 . 2}$ & $\mathbf{- 1 1 . 0}$ \\
35 & $\mathbf{- 8 . 0}$ & -5.0 & -2.6 & -0.9 & 0.0 & 0.2 & -0.4 & -1.8 & -3.9 & $\mathbf{- 6 . 9}$ & $\mathbf{- 1 0 . 6}$ \\
40 & $\mathbf{- 8 . 3}$ & $\mathbf{- 5 . 2}$ & -2.7 & -1.0 & 0.0 & 0.3 & -0.3 & -1.6 & -3.6 & $\mathbf{- 6 . 5}$ & $\mathbf{- 1 0 . 1}$ \\
45 & $\mathbf{- 8 . 6}$ & $\mathbf{- 5 . 4}$ & -2.9 & -1.1 & 0.0 & 0.3 & -0.1 & -1.3 & -3.3 & $\mathbf{- 6 . 1}$ & $\mathbf{- 9 . 7}$ \\
50 & $\mathbf{- 8 . 9}$ & $\mathbf{- 5 . 6}$ & -3.0 & -1.2 & 0.0 & 0.4 & 0.1 & -1.1 & -3.0 & $\mathbf{- 5 . 7}$ & $\mathbf{- 9 . 3}$ \\
55 & $\mathbf{- 9 . 1}$ & $\mathbf{- 5 . 8}$ & -3.2 & -1.2 & 0.0 & 0.5 & 0.2 & -0.8 & -2.7 & $\mathbf{- 5 . 4}$ & $\mathbf{- 8 . 8}$ \\
60 & $\mathbf{- 9 . 4}$ & $\mathbf{- 6 . 1}$ & -3.4 & -1.3 & 0.0 & 0.6 & 0.4 & -0.6 & -2.4 & -5.0 & $\mathbf{- 8 . 4}$ \\
65 & $\mathbf{- 9 . 7}$ & $\mathbf{- 6 . 3}$ & -3.5 & -1.4 & 0.0 & 0.7 & 0.5 & -0.4 & -2.1 & -4.6 & $\mathbf{- 8 . 0}$ \\
70 & $\mathbf{- 1 0 . 0}$ & $\mathbf{- 6 . 5}$ & -3.6 & -1.5 & 0.0 & 0.7 & 0.7 & -0.1 & -1.8 & -4.2 & $\mathbf{- 7 . 5}$ \\
75 & $\mathbf{- 1 0 . 2}$ & $\mathbf{- 6 . 7}$ & -3.8 & -1.6 & 0.0 & 0.8 & 0.9 & 0.1 & -1.4 & -3.8 & $\mathbf{- 7 . 1}$ \\
80 & $\mathbf{- 1 0 . 5}$ & $\mathbf{- 6 . 9}$ & -3.9 & -1.6 & 0.0 & 0.9 & 1.0 & 0.4 & -1.1 & -3.4 & $\mathbf{- 6 . 6}$ \\
85 & $\mathbf{- 1 0 . 7}$ & $\mathbf{- 7 . 1}$ & -4.1 & -1.7 & 0.0 & 1.0 & 1.2 & 0.6 & -0.8 & -3.0 & $\mathbf{- 6 . 1}$ \\
90 & $\mathbf{- 1 1 . 0}$ & $\mathbf{- 7 . 3}$ & -4.2 & -1.8 & 0.0 & 1.1 & 1.4 & 0.9 & -0.5 & -2.6 & $\mathbf{- 5 . 7}$ \\
95 & $\mathbf{- 1 1 . 3}$ & $\mathbf{- 7 . 5}$ & -4.4 & -1.9 & 0.0 & 1.1 & 1.5 & 1.1 & -0.1 & -2.2 & $\mathbf{- 5 . 2}$ \\
100 & $\mathbf{- 1 1 . 5}$ & $\mathbf{- 7 . 7}$ & -4.5 & -1.9 & 0.0 & 1.2 & 1.7 & 1.4 & 0.2 & -1.8 & -4.7 \\
\hline
\end{tabular}

\subsection{Teat diameter}

Linear regression showed that the diameter of the different artificial teats can be predicted from the diameter measured by the measuring device (adjusted coefficient of determination $R^{2}=0.999 \pm 0.274$, $0.991 \pm 0.811,0.997 \pm 0.445$ and $0.970 \pm 1.507$ for D75, D50, D25 and D10, respectively). These already high values of $\mathrm{R}^{2}$ were slightly increased $(\mathrm{P}<0.001)$ by adding the angle of the artificial teat in the longitudinal direction $(\beta)$ to the model $1.00 \pm 0.185,0.994 \pm 0.673,0.999 \pm 0.269$ for D75, D50 and $\mathrm{D} 25$, respectively. No significant contribution of $\beta$ was found for $\mathrm{D} 10(\mathrm{P}=0.842)$.

The percentage deviation of the teat diameters at $75 \%, 50 \%$ and $25 \%$ of the teat was significantly affected by the teat diameter of the artificial teat $(\mathrm{P}<0.001)$, whereas no significant influence of the teat diameter on the percentage deviation was found for $\mathrm{D} 10(\mathrm{P}=0.272)$. In addition, the percentage deviations at all heights significantly depended on the interaction between teat length and $\beta(\mathrm{P}<$ 0.001) (Table 2). Teats positioned straight through the opening of the profile gave almost no inaccuracies for all teat lengths. Errors increase with increasing angles in both directions. Yet, these errors are restricted to 5\% for D75, D50 and D25. At very small angles, the error was even lower than $2 \%$. Moreover, the errors made by the device at different angles for different teat lengths were not 
significantly different from the errors when the teat was placed straight in the device, except at large angles. In contrast, at the teat end (D10), large underestimations of diameters were observed for most angles and the errors were larger for shorter teats than for longer teats. The data showed an increase in deviation of measured diameters compared to the actual diameters from teat base to barrel, both for teats pointing towards (overestimation) and away (underestimation) from the camera.

\section{Discussion}

The images of the teats taken with the measuring device were all of good quality for image processing analysis. Due to the regularly dispersed background light, the contour of the teat could be easily identified. For teats that made an angle in the transverse direction, a standard correction was integrated in the software program for both teat length and teat diameter. In this study, the accuracy of the teat measuring device was under investigation, i.e. the ability to give a true measure of the object of interest. The calculated error on the length of teats that make an angle in the longitudinal direction was less than $2 \%$ for teats at small angles and was in general less than 5\%, although larger angles caused larger errors. Since this angle cannot be measured under field conditions, no correction factor can be incorporated in the analysis. It was therefore concluded that care should be taken by the operator to put the teat in the device as straight as possible.

For diameters, regression analysis indicates that the measured teat diameter was a good predictor for the teat diameter at all heights and for different teat lengths. Adding $\beta$ to the regression model only slightly increased the precision of the diameter prediction. Errors were mostly limited to 5\%. These errors significantly depended on the interaction between teat length and $\beta$. Errors at different angles for different teat lengths did not significantly differ from the errors when the teat was placed straight in the device, except at large angles but even then they were mostly less than 5\%. Errors generally increased with increasing deviation in the longitudinal direction due to the increasing shift away from the centre towards or away from the camera. As errors in the diameter were calculated at relative heights, the height at which the diameter was measured varied with the teat length. For this reason, the error on the teat diameter also depended on the error of the teat length at a certain angle. This emphasised the importance of placing the teat in the device as straight as possible. Errors at the teat base (D75) were usually smaller than those at the barrel (D50) since, under the same angle, lower diameters are moved more towards or away from the camera. For the same reason, errors at the teat base and the barrel increase with increasing length. Large errors, that exceed $10 \%$, occured at the teat end (D10). In contrast, the largest errors at the teat end were found for short teats and the errors decreased with increasing length. It should be kept in mind that diameters at different heights of the teat were being compared. For a short teat of $30 \mathrm{~mm}$ the diameter at $10 \%$ of the teat was measured at 3 $\mathrm{mm}$ from the top, whilst for a long teat of $90 \mathrm{~mm}$ this corresponded to a point $9 \mathrm{~mm}$ from the top. 
Table 2 - Average percentage deviation on teat diameters at 75\%,50\%,25\% and 10\% of the teat, starting from the teat end, for artificial teats of different length $(30 \mathrm{~mm}, 50 \mathrm{~mm}, 70 \mathrm{~mm}$ and $90 \mathrm{~mm})$ under various angles in the longitudinal direction $\left(-20^{\circ}\right.$ to $30^{\circ}$ towards the camera $)$, with deviations $>5 \%$ in bold.

\begin{tabular}{|c|c|c|c|c|c|c|c|c|c|c|c|c|c|c|c|c|}
\hline \multirow{3}{*}{$\begin{array}{l}\text { Angle in the } \\
\text { longitudinal } \\
\text { direction of } \\
\text { the camera } \\
\left({ }^{\circ}\right)\end{array}$} & \multicolumn{16}{|c|}{ Teat length } \\
\hline & \multicolumn{4}{|c|}{$30 \mathrm{~mm}$} & \multicolumn{4}{|c|}{$50 \mathrm{~mm}$} & \multicolumn{4}{|c|}{$70 \mathrm{~mm}$} & \multicolumn{4}{|c|}{$90 \mathrm{~mm}$} \\
\hline & D75 & D50 & D25 & D10 & D75 & D50 & D25 & D10 & D75 & D50 & $\mathrm{D} 25$ & D10 & D75 & D50 & D25 & D10 \\
\hline-20 & -0.6 & -1.3 & $-5.1 *$ & -11.7 & $-1.1 *$ & -1.4 & -4.4 & -7.5 & & & & & & & & \\
\hline-15 & -0.4 & -1.1 & -3.9 & -9.2 & 0.1 & -1.0 & -3.3 & -5.9 & -1.1 & $-2.2 *$ & -4.1 & -5.8 & & & & \\
\hline-10 & -0.4 & -0.9 & -2.4 & -6.9 & 0.2 & -0.2 & -2.4 & -5.5 & -0.6 & -0.8 & -3.1 & -4.6 & -1.1 & -1.4 & -3.0 & -4.9 \\
\hline-5 & -0.3 & -0.7 & -1.3 & -3.1 & 0.3 & -0.3 & -1.8 & -2.1 & 0.2 & -0.3 & -1.9 & -2.7 & -0.1 & -0.6 & -1.1 & -2.6 \\
\hline 0 & -0.1 & -0.6 & -0.1 & 0.6 & 0.6 & 0.3 & -1.2 & -0.7 & 0.5 & 0.1 & -1.3 & -1.1 & 0.5 & 0.2 & -0.6 & -1.0 \\
\hline 5 & 0.2 & -0.2 & -0.5 & -1.3 & 0.8 & 0.5 & -0.9 & 0.5 & 0.4 & 0.4 & -0.6 & 0.8 & 0.3 & 0.6 & 0.5 & 0.4 \\
\hline 10 & 0.2 & -0.2 & -0.7 & -4.8 & 0.9 & 1.0 & -0.1 & -1.0 & 0.7 & 1.1 & 0.4 & 0.4 & 1.0 & 1.3 & 1.6 & 1.7 \\
\hline 15 & 0.2 & 0.0 & -2.1 & -12.9 & 1.2 & 1.4 & 0.4 & -3.3 & 1.0 & 1.5 & 1.4 & -0.5 & 1.4 & $2.1^{*}$ & 2.5 & 1.8 \\
\hline 20 & 0.3 & 0.5 & -2.9 & -11.4 & 1.3 & 1.7 & 0.9 & -5.6 & 1.4 & $2.3^{*}$ & 2.1 & -1.0 & 1.8 & $2.6^{*}$ & 3.2 & 1.0 \\
\hline 25 & 0.7 & 0.6 & -3.6 & -12.7 & 1.4 & $2.3^{*}$ & 0.7 & -7.1 & 1.5 & $2.9 *$ & 2.7 & -2.7 & $2.2^{*}$ & $3.4^{*}$ & $4.3^{*}$ & 1.1 \\
\hline 30 & 0.6 & 0.7 & -4.0 & -11.6 & 1.8 & $2.5^{*}$ & 1.3 & -6.5 & $2.0 *$ & $3.1^{*}$ & $3.5^{*}$ & -2.3 & $2.4^{*}$ & $4.0 *$ & $5.1 *$ & 1.0 \\
\hline
\end{tabular}

* Significantly different from value at $0^{\circ}$ within column $(\mathrm{P}<0.05)$ 
Some researchers determine teat diameter at a defined distance from the teat end (Borkhus \& Ronningen, 2003; Chrystal, Seykora, Hansen, 1999). These absolute measures are more clear-cut. However, both relative as well as absolute measures contain valuable information. From the images made with the $2 \mathrm{D}$ vision based measuring device, both relative as absolute teat dimensions can be deduced, providing a large amount of information that can be used for a wide range of purposes. Depending on the topic under investigation, relative or absolute dimensions will be used. Research on the selection of teatcup liners based on teat dimensions will use absolute measures. To determine whether a liner is too small or too broad at a specific point for a certain teat, the diameter of the liner has to be compared to the diameter of the teat at that point. Consequently, absolute measures are required in liner selection, whilst relative measures are mainly used for descriptive herd studies since it is important to compare the same area (teat end, barrel or base), when comparing teats.

As for teat length, this is the first study, to our knowledge, that calculates the percentage difference of the measured values compared to the actual diameters of artificial teats. A high degree of accuracy $( \pm$ 2\%) was reported for the modified cutimeter (Hamann \& Mein, 1988). However, it was not clearly stated how this result was obtained. A similar accuracy of $2 \%$ was found with the $2 \mathrm{D}$ vision based measuring technique presented in this study, both for teat length and diameters, except for diameters at the teat end and as long as the instructions for the measuring device are followed, i.e. when the teat is put straight in the device. When this is done, the accuracy of the technique is sufficient to measure the variation in teat length between front and rear teats (difference on average 8 to 19\%) and between parity; Wufka \& Willeke (2001) reported a difference of 5.3\% between first and second lactation, and of $2.5 \%$ between second and third lactation. Since the errors at the teat end can be greater than $10 \%$, further research is needed to examine whether the measuring technique could be applied in determining the diameters at the teat end. Artificial teats of various teat shapes as well as real teats should be subject of this study.

Besides accuracy, a coefficient of variation of $8-10 \%$, a measure for repeatability, was observed for the modified cutimeter, whilst better results $(2 \%)$ were found for the electronic calliper device (Hamann et al., 1988). Although the cutimeter can measure teat diameters, it is usually used to measure changes in teat tissue due to milking. As a result, the high degree of accuracy and repeatability could be applicable to changes in teat tissue instead of teat diameter measurements. Good repeatability (3.6\% difference between duplicate measurements and $4.4 \%$ difference between days) was also attained by use of ultrasonography for teat end diameter (Neijenhuis et al., 2001). These results reflect the consistency of measurements repeated with the same technique, regardless of whether or not the values are correct, as a measure for precision, which differs from the accuracy investigated in this study. To assess if the developed measuring device can be used to determine teat dimensions in field conditions precise and accurate, determination of the repeatability and 
reproducibility of the device, as well as comparison with a standard, will be subjects of subsequent studies.

\section{Conclusion and future perspectives}

A new 2D vision based measuring method has been presented in this study. The use of image analysis permits a fast and objective measurement of teat shape parameters. The method has been proven to be accurate for teat dimensions: errors are generally less than 5\% and less than $2 \%$ when the angle of the teat in the longitudinal direction is small. Special attention must therefore be paid on putting the teats straight into the measuring device. Further research is needed to evaluate the repeatability and the reproducibility of the measuring technique under field conditions and to examine whether the measuring technique can be applied in determining the diameters of the teat end and consequently be used for teat (end) shape classification. Artificial teats of various shapes as well as real teats should be subject of this study. Because the measuring technique makes it possible to gather information on a large scale, both in experimental and field conditions, it allows identification and investigation of the factors influencing teat dimensions. Additionally, since information of the whole teat is available, liner performance can be evaluated in relation to teat dimensions by assessing udder health and milking characteristics. In the short term the information generated using the measuring device may enable better selection of teatcup liners adapted to the herd. In the longer term, the information may lead to more uniform teat dimensions within a herd through selective breeding, which may simplify liner choice. Better liner selection may in turn, result in better teat condition, decreasing the incidence of intramammary infections and thereby improving the quality and the quantity of the milk yield.

\section{Acknowledgements}

This research was funded by the Institute for the Promotion of Innovation through Science and Technology in Flanders (IWT-Vlaanderen, grant no. 50670) and the Institute for Agricultural and Fisheries Research (ILVO, PhD scholarship). The authors would like to thank the technical staff of ILVO for the construction of the measuring device. 


\section{References}

Ambord, S., \& Bruckmaier, R. M. (2010). Milk flow-dependent vacuum loss in high-line milking systems: Effects on milking characteristics and teat tissue condition. Journal of Dairy Science, 93(8), 3588-3594.

Baert, J., Maertens, W., Vangeyte, J., \& Sonck, B. (2007). Development of a prototype for measuring teat dimensions used as parameters for teat cup liner selection. In: Proceedings of IDF International Symposium on advances in milking, 55-57.

Bakken, G. (1981). Relationships between udder and teat morphology, mastitis and milkproduction in Norwegian Red Cattle. Acta Agriculturae Scandinavica, 31(4), 438-444.

Bhutto, A. L., Murray, R. D., \& Woldehiwet, Z. (2010). Udder shape and teat-end lesions as potential risk factors for high somatic cell counts and intra-mammary infections in dairy cows. Veterinary Journal, 183(1), 63-67.

Borkhus, M., \& Ronningen, O. (2003). Factors affecting mouthpiece chamber vacuum in machine milking. Journal of Dairy Research, 70(3), 283-288.

Chrystal, M. A., Seykora, A. J., \& Hansen, L. B. (1999). Heritabilities of teat end shape and teat diameter and their relationships with Somatic Cell Score. Journal of Dairy Science, 82(9), 2017 2022.

de Koning, K., Ronningen, O., Bjerring, M., \& Ipema, B. (2003). Testing of liners and measuring material properties. In: Proceedings of 100 years with Liners and Pulsators, 499-506.

Gleeson, D. E., O'Callaghan, E. J., \& Rath, M. V. (2004). Effect of liner design, pulsator setting, and vacuum level on bovine teat tissue changes and milking characteristics as measured by ultrasonography. Irish Veterinary Journal, 57(5), 289-296.

Hamann, J., \& Mein, G. A. (1988). Responses of the bovine teat to machine milking: measurement of changes in thickness of the teat apex. Journal of Dairy Research, 55(3), 331-338.

Hamann, J., Mein, G. A., \& Nipp, B. (1996). Recommended method for measuring changes in thickness of the bovine teat with spring-loaded calipers. Journal of Dairy Research, 63(2), 309-313.

Hamann, J., Nipp, B., \& Mein, G. A. (1988). Improving milk quality by improving teat condition: a new method for measuring teat tissue-reactions to milking. Milchwissenschaft-Milk Science International, 43(10), 651-653.

Marie-Etancelin, C., Casu, S., Aurel, M. R., Barilett, F., Carta, A., Deiana, S., ... (2002). New tools to appraise udder morphology and milkability in dairy sheep. CIHEAM - Options Mediteraneennes. Retrieved from http://ressources.ciheam.org/om/pdf/a55/03600065.pdf

McKusick, B. C., Berger, Y. M., \& Thomas, D. L. (1999). Preliminary results: effects of udder morphology on commercial milk production of East Friesian crossbred ewes. In: Proceedings of the 5th Great Lakes Dairy Sheep Symposium, 49-60. 
Mein, G. A., Reinemann, D. J., O'Callaghan, E., \& Ohnstad, I. (2003). Where the rubber meets the teat and what happens to milking characteristics. In: Proceedings of 100 years with Liners and Pulsators, 431-438.

Neijenhuis, F., Klungel, G. H., \& Hogeveen, H. (2001). Recovery of cow teats after milking as determined by ultrasonographic scanning. Journal of Dairy Science, 84(12), 2599-2606.

Paulrud, C. O., Clausen, S., Andersen, P. E., \& Rasmussen, M. D. (2005). Infrared thermography and ultrasonography to indirectly monitor the influence of liner type and overmilking on teat tissue recovery. Acta Veterinaria Scandinavica, 46(3), 137-147.

Rovai, M., Kollmann, M. T., \& Bruckmaier, R. M. (2007). Incontinentia lactis: Physiology and anatomy conducive to milk leakage in dairy cows. Journal of Dairy Science, 90(2), 682-690.

Sapp, R. L., Rekaya, R., \& Bertrand, J. K. (2003). Simulation study of teat score in first-parity Gelbvieh cows: Parameter estimation. Journal of Animal Science, 81(12), 2959-2963.

Seker, I., Risvanli, A., Yuksel, M., Saat, N., \& Ozmen, O. (2009). Relationship between California Mastitis Test score and ultrasonographic teat measurements in dairy cows. Australian Veterinary Journal, 87(12), 480-483.

Tilki, M., Inal, S., Colak, M., \& Garip, M. (2005). Relationships between milk yield and udder measurements in Brown Swiss Cows. Turkish Journal of Veterinary \& Animal Sciences, 29(1), 75-81.

World Holstein-Friesian Federation (2005). International type evaluation of dairy cattle. Retrieved from http://www.whff.info/info/typetraits/type en 2005-2.pdf

Zavadilova, L., Stipkova, M., Nemcova, E., Bouska, J., \& Matejickova, J. (2009). Analysis of the phenotypic relationships between type traits and functional survival in Czech Fleckvieh cows. Czech Journal of Animal Science, 54(12), 521-531. 